ఠ

Open Access Full Text Article

REVIEW

\title{
Apixaban for the prophylaxis and treatment of deep vein thrombosis and pulmonary embolism: an evidence-based review
}

This article was published in the following Dove Press journal:

Therapeutics and Clinical Risk Management

26 August 2015

Number of times this article has been viewed

\section{Molly W Mandernach' \\ Rebecca J Beyth ${ }^{1,2}$ \\ Anita Rajasekhar'}

'Division of Hematology and Oncology, College of Medicine, University of

Florida, Gainesville, FL, USA; ${ }^{2}$ North

Florida/South Georgia Veterans

Health System (NF/SGVHS), Geriatric

Research, Education and Clinical

Center (GRECC), Gainesville, FL, USA
Correspondence: Molly W Mandernach University of Florida Department of Medicine, Division of Hematology/ Oncology 1600 SW Archer Road, PO Box 100278, Gainesville, FL 32610, USA Tel +l 3522737832

Fax +l 3522735006

Email molly.weidner@medicine.ufl.edu
Abstract: Venous thromboembolism (VTE) results in significant morbidity and mortality. The prevention and treatment of VTE is managed with anticoagulant therapy, historically parenteral anticoagulants such as unfractionated heparin, low molecular weight heparin, and fondaparinux, and oral vitamin $\mathrm{K}$ antagonists such as warfarin. In the last few years, several target-specific oral anticoagulants have been developed, including the direct thrombin inhibitor dabigatran and anti-Xa inhibitors rivaroxaban, apixaban, and edoxaban. The target-specific oral anticoagulants have proven to be noninferior to vitamin $\mathrm{K}$ antagonists and heparins in the prevention and treatment of VTE. This review will focus on the pharmacology, clinical trial data, and laboratory assessment of apixaban. Moreover, perioperative management, use in special populations, and management of bleeding complications in patients taking apixaban for the prevention and treatment of VTE will also be discussed.

Keywords: venous thromboembolism, apixaban, new oral anticoagulant, target-specific oral anticoagulant, thromboprophylaxis

\section{Introduction}

Deep vein thrombosis (DVT) and pulmonary embolism (PE), collectively termed venous thromboembolism (VTE), results in significant morbidity and mortality. In the US, an estimated 350,000-600,000 individuals develop VTE annually, resulting in approximately 100,000 deaths. ${ }^{1}$ Additionally, $30 \%-50 \%$ of individuals with lower-extremity DVT develop post-thrombotic syndrome which can be painful and debilitating. ${ }^{2}$ Approximately $10 \%-30 \%$ of individuals who survive the first occurrence of VTE will develop another VTE within 5 years, ${ }^{3}$ and the economic burden of VTE in the US has been estimated at more than $\$ 1.5$ billion per year. ${ }^{4}$

The pathophysiology involved in the development of VTE is predicated upon the presence of hypercoagulability, venous stasis, or localized vascular endothelial injury. Individual characteristics leading to one or all of this triad include advanced age, prolonged immobility, previous VTE, pregnancy or the postpartum state, cancer, hospitalization, surgery, trauma, and thrombophilia. ${ }^{5}$

Anticoagulant therapy is essential in the prevention and treatment of VTE. Historically, parenteral anticoagulants have been utilized to include unfractionated heparin (UFH), low molecular weight heparin (LMWH), and the indirect anti-factor Xa inhibitor fondaparinux. The limitations of the parenteral anticoagulants include requirement for IV access and administration, the discomfort of subcutaneous injections, dependence on renal clearance (LMWH and fondaparinux), osteoporosis and heparin-induced thrombocytopenia with UFH and LMWH, and laboratory monitoring. Vitamin K antagonists (VKAs) such as 
warfarin are used extensively in the prevention and treatment of VTE and prevention of stroke and systemic embolism in patients with atrial fibrillation or mechanical heart valves. Although warfarin has been utilized for over 60 years, it has several limitations, including a slow onset of action, a narrow therapeutic window requiring routine international normalized ratio (INR) monitoring, lack of predictable anticoagulant effect by drug dose, and multiple factors that influence absorption such as drug-drug interactions, altered metabolism due to genetic variations, altered vitamin $\mathrm{K}$ balance, impaired liver function, and hypermetabolic states such as fever or hyperthyroidism. ${ }^{6-10}$ In the last 5 years, four new target-specific oral anticoagulants (TSOACs), dabigatran, rivaroxaban, apixaban, and edoxaban, have been approved for various indications. ${ }^{11-14}$ The advantages of these TSOACs are the lack of need for routine laboratory monitoring, a rapid onset of action with a predictable anticoagulant effect, once or twice daily fixed dosing, and low potential for food and drug interactions.

Currently, apixaban is US FDA-approved to reduce the risk of stroke and systemic embolism in patients with nonvalvular atrial fibrillation, for the prophylaxis of DVT, which may lead to $\mathrm{PE}$, in patients who have undergone hip or knee replacement surgery, for the treatment of DVT and PE, and for the reduction in the risk of recurrent DVT and PE following initial therapy. ${ }^{13}$

In this article, we will review the pharmacology, clinical trial data leading to FDA approved indications, and practical aspects related to the use of apixaban in the prevention and treatment of VTE.

\section{Pharmacodynamics and pharmacokinetics}

Apixaban is a selective factor $\mathrm{Xa}(\mathrm{FXa})$ inhibitor that does not require antithrombin for its antithrombotic activity. It inhibits both free and clot-bound FXa as well as prothrombinase activity. It indirectly inhibits platelet aggregation induced by thrombin, and decreases thrombin generation and thus fibrin clot development. Apixaban prolongs the prothrombin time (PT), INR, and activated partial thromboplastin time (aPTT) through its anti-FXa activity. Prolongation of these assays is subject to a high degree of variability and should not be used in the routine monitoring of the anticoagulation effect of apixaban. Apixaban demonstrates linear pharmacokinetics with dose-proportional increases in exposure for oral doses up to $10 \mathrm{mg}$. Bioavailability is approximately $50 \%$ through gastrointestinal absorption and maximum concentrations occur 3-4 hours following oral administration. Apixaban is highly protein bound thus is nondialyzable. It is metabolized mainly by the hepatic CYP3A4 system and is a substrate for the P-glycoprotein and breast cancer resistance proteins. Apixaban has a half-life of approximately 12 hours following oral administration with renal excretion accounting for approximately $27 \%$ of total clearance and biliary and direct intestinal excretion contributing to the remainder of the elimination in feces. The elimination half-life is prolonged in renal impairment. ${ }^{13,15-17}$ Additional pharmacokinetic details are delineated in Table 1.

\section{Primary prevention of VTE after orthopedic surgery}

The estimated cumulative postoperative rate for symptomatic VTE up to 35 days after major orthopedic surgery is $4.3 \%$ without pharmacologic prophylaxis. VTE continues to be recognized as a significant risk in patients undergoing total hip replacement (THR) or total knee replacement (TKR), and approximately 200,000 procedures for THR are performed in the US each year. ${ }^{18}$ The American College of Chest

Table I Apixaban pharmacokinetics and pharmacodynamics ${ }^{13,15-17}$

\begin{tabular}{ll}
\hline Mechanism of action & Factor Xa inhibitor \\
Bioavailability & $50 \%$, gastrointestinal \\
$T$ (max) & $3-4$ hours \\
Distribution & $87 \%$ protein bound \\
Half-life & $8-13$ hours (prolonged in renal impairment) \\
Monitoring & None required. Anti-Xa assay useful in determining if anticoagulant effect present \\
Dosing & Nonvalvular atrial fibrillation: $5 \mathrm{mg}$ twice daily \\
& THR prophylaxis: $2.5 \mathrm{mg}$ twice daily for 35 days \\
& TKR prophylaxis: $2.5 \mathrm{mg}$ twice daily for 12 days \\
& VTE treatment: $10 \mathrm{mg}$ twice daily for 7 days, then $5 \mathrm{mg}$ twice daily \\
& Prophylaxis of recurrent VTE: $2.5 \mathrm{mg}$ twice daily after at least 6 months of treatment \\
Dose adjustments & In patients with nonvalvular atrial fibrillation and at least two of the following: \\
& Age $\geq 80$ years, body weight $\leq 60 \mathrm{~kg}$, or serum creatinine $\geq 1.5 \mathrm{mg} / \mathrm{dL}$, recommended dose is $2.5 \mathrm{mg}$ twice daily \\
Metabolism & Hepatic CYP3A4 system \\
Elimination & $25 \%$ renal, $75 \%$ biliary \\
Drug interactions & Potent P-gp and CYP3A4 inhibitors or inducers \\
\hline
\end{tabular}

Abbreviations: THR, total hip replacement; TKR, total knee replacement; VTE, venous thromboembolism; P-glycoprotein. 
Physicians recommends the use of LMWH, fondaparinux, apixaban, dabigatran, rivaroxaban, low dose UFH, adjusted dose VKA, or aspirin (all Grade 1B) for 10-14 days rather than no antithrombotic prophylaxis. Apixaban is FDAapproved for the primary prevention of DVT, which may lead to PE, following hip or knee replacement surgery based upon the following trials.

The ADVANCE-1 and ADVANCE-2 trials were large Phase III clinical trials that evaluated apixaban following TKR for 10-14 days. Both were designed as noninferiority trials. In the ADVANCE-1 trial, apixaban $2.5 \mathrm{mg}$ daily was compared to enoxaparin $30 \mathrm{mg}$ subcutaneous twice daily. ${ }^{19}$ Both medications were initiated 12 hours following surgery. A total of 1,599 patients received apixaban and 1,596 patients were randomized to the enoxaparin arm. In the ADVANCE-2 trial, patients were randomized to receive apixaban $2.5 \mathrm{mg}$ twice daily $(n=1,528)$ or subcutaneous enoxaparin $40 \mathrm{mg}$ once daily $(n=1,529) .{ }^{20}$ Apixaban was initiated 12-24 hours following wound closure and enoxaparin was initiated 12 hours prior to surgery. Surveillance bilateral venography was performed after 10-14 days in all patients in both studies. Exclusion criteria for both trials included active bleeding or a contraindication to anticoagulant prophylaxis, patients requiring ongoing anticoagulant or antiplatelet treatment, uncontrolled hypertension, active hepatobiliary disease, clinically significant renal impairment defined as creatinine clearance $(\mathrm{CrCl})<30 \mathrm{~mL} / \mathrm{min}$, thrombocytopenia defined as platelet count $<100,000 / \mathrm{mm}^{3}$, anemia defined as hemoglobin $<10 \mathrm{~g} / \mathrm{dL}$, allergy to heparin, allergy to radiographic contrast dye, or other contraindication to bilateral venography. The primary efficacy outcome for both trials was a composite of asymptomatic or symptomatic DVT, nonfatal PE, and death from any cause. The primary safety outcome was bleeding reported during treatment (or within 2 days of the last dose of study medication in the ADVANCE-1 trial) including major bleeding, clinically relevant nonmajor (CRNM) bleeding, minor bleeding, and the composite of major bleeding and CRNM bleeding. The definition of major bleeding was adapted from the criteria for bleeding in nonsurgical patients of the International Society of Thrombosis and Haemostasis. ${ }^{21}$ In the ADVANCE-1 trial, the primary efficacy outcome occurred in $9.0 \%$ of patients on the apixaban arm versus $8.8 \%$ for the enoxaparin arm (risk ratio [RR] 1.02 [95\% confidence interval $\{\mathrm{CI}\} 0.78-1.32], P=0.06)$. The primary safety outcome occurred in $2.9 \%$ in the apixaban arm and $4.3 \%$ in the enoxaparin arm (adjusted difference in event rates according to type of surgery, $-1.46 \%[95 \% \mathrm{CI}-2.75 \%$ to $-0.17 \%], P=0.03$ ). In the ADVANCE- 2 trial, the primary outcome occurred in $15 \%$ of patients randomized to apixaban and
$24 \%$ on enoxaparin (RR 0.62 [95\% CI $0.51-0.74], P<0.0001$ ). Major or CRNM bleeding occurred in $4 \%$ of the apixaban group versus $5 \%$ of the enoxaparin arm $(P=0.09)$. Thus, the ADVANCE-2 trial established noninferiority of apixaban in the setting of VTE prophylaxis for TKR. A meta-analysis of three randomized trials of apixaban therapy compared with enoxaparin involving 7,337 individuals, of whom 4,057 were treated with apixaban $2.5 \mathrm{mg}$ once daily and 3,280 with subcutaneous enoxaparin ( $40 \mathrm{mg}$ once daily or $30 \mathrm{mg}$ twice daily) confirmed that apixaban was associated with a lower major bleeding rate than enoxaparin in the setting of post-TKR (odds ratio [OR] 0.55 [95\% CI 0.32-0.96], $P=0.034){ }^{22}$

Data from the ADVANCE-3 trial led to the FDA approval of apixaban for prevention of DVT following hip replacement surgery. ${ }^{23}$ In this study, 5,407 patients undergoing THR or revision of a previously inserted hip prosthesis were randomly assigned to receive apixaban $2.5 \mathrm{mg}$ orally twice daily or enoxaparin $40 \mathrm{mg}$ subcutaneously daily. Apixaban was initiated 12-24 hours following wound closure and enoxaparin 12 hours prior to surgery. Prophylaxis was administered for 35 days following surgery at which time bilateral venograms were performed. Exclusion criteria were identical to ADVANCE-1 and ADVANCE-2. Efficacy outcomes (composite of asymptomatic or symptomatic DVT, nonfatal PE, or all cause death) occurred in $1.5 \%$ in the apixaban arm versus $3.9 \%$ in the enoxaparin arm (RR 0.36 [95\% CI 0.22-0.54], $P \leq 0.001$ for both noninferiority and superiority). Major and CRNM bleeding occurred in $4.8 \%$ of the patients assigned to apixaban and $5.0 \%$ in the enoxaparin arm (absolute difference in risk, $-0.2 \%$ [95\% CI $-1.4 \%$ to $1.0 \%$ ], $P=0.72$ ). Thus, the ADVANCE-3 trial proved efficacy and safety of apixaban in the prevention of VTE after THR.

\section{Treatment and secondary prevention of VTE}

The AMPLIFY trial was a randomized double-blind study that compared the efficacy and safety of apixaban $(10 \mathrm{mg}$ twice daily for 7 days followed by $5 \mathrm{mg}$ twice daily) with subcutaneous enoxaparin $1 \mathrm{mg} / \mathrm{kg}$ every 12 hours for at least 5 days followed by warfarin (goal INR 2-3) in a total of 5,395 patients with acute VTE. ${ }^{24}$ Treatment in both arms was for 6 months. Patients were excluded for active bleeding, high risk of bleeding, or other contraindications to treatment with enoxaparin and warfarin; for cancer with planned long-term treatment with LMWH; provoked DVT or PE by a temporary risk factor; if less than 6 months of anticoagulant treatment was planned; or if they fulfilled another indication for long-term anticoagulation therapy, dual antiplatelet therapy, treatment with aspirin at a dose of more than $165 \mathrm{mg}$ daily, or 
treatment with potent inhibitors of the cytochrome P-450 3A4 system. Patients were also excluded if they had received more than two doses of a once-daily LMWH, fondaparinux, or a VKA; more than three doses of twice-daily LMWH; more than 36 hours of continuous intravenous heparin; hemoglobin less than $9 \mathrm{mg} / \mathrm{dL}$, platelet count less than $100,000 / \mathrm{mm}^{3}$, serum creatinine $>2.5 \mathrm{mg} / \mathrm{dL}$, or calculated $\mathrm{CrCl}<25 \mathrm{~mL} / \mathrm{min}$. The primary efficacy outcome was recurrent symptomatic VTE or death related to VTE. The principal safety outcomes were major bleeding alone as defined by International Society on Thrombosis and Haemostasis and major bleeding plus CRNM bleeding. ${ }^{21}$ In the apixaban group, adherence to therapy was at least $80 \%$ in $96 \%$ of the patients, while the INR was therapeutic (2.0-3.0) $61 \%$ of the time in the conventional therapy group. The primary efficacy outcome occurred in $2.3 \%$ of patients in the apixaban group and in $2.7 \%$ in the conventional therapy group (RR 0.84 [95\% CI 0.60-1.18], $P<0.001$ for noninferiority). Major bleeding occurred in $0.6 \%$ of the apixaban arm and $1.8 \%$ in the conventional therapy group (RR 0.31 [95\% CI 0.17-0.55], $P<0.001$ for superiority). Thus, apixaban was proven to be noninferior to standard medical therapy for VTE and superior with respect to bleeding risk.

In the AMPLIFY-EXT study, Agnelli et al further evaluated the use of apixaban for extended prophylaxis following initial treatment for VTE. ${ }^{25}$ This randomized double-blind trial compared two doses of apixaban $(2.5 \mathrm{mg}$ and $5 \mathrm{mg}$, twice daily) with placebo in patients with VTE who had completed 6-12 months of anticoagulation therapy. The study medications were administered for 12 months. Patients were ineligible if they had a contraindication to continued anticoagulant therapy or if they required ongoing anticoagulant therapy, dual antiplatelet therapy, or aspirin at a dose higher than $165 \mathrm{mg}$ daily, hemoglobin level less than $9 \mathrm{mg} / \mathrm{dL}$, platelet count less than $100,000 / \mathrm{mm}^{3}$, serum creatinine level greater than $2.5 \mathrm{mg} / \mathrm{dL}$ or a calculated $\mathrm{CrCl}$ of less than $25 \mathrm{~mL} / \mathrm{min}$, alanine aminotransferase or aspartate aminotransferase level more than two times the upper limit of the normal range, or total bilirubin level more than 1.5 times the upper limit of the normal range. The primary efficacy outcome was the composite of symptomatic recurrent VTE or death from any cause; however, symptomatic recurrent VTE or death related to VTE was a prespecified secondary efficacy outcome. The primary safety outcome was major bleeding as defined by International Society on Thrombosis and Haemostasis, and the secondary safety outcome was the composite of major or CRNM bleeding. ${ }^{21}$ Symptomatic recurrent VTE or death from VTE occurred in $8.8 \%$ of the placebo arm compared to $1.7 \%$ receiving $2.5 \mathrm{mg}$ of apixaban (RR 0.19 [95\% CI 0.11-0.33], $P<0.001)$ and $1.7 \%$ of the patients who were receiving $5 \mathrm{mg}$ of apixaban (RR 0.20 [95\% CI 0.11-0.34], $P<0.001)$. For apixaban $2.5 \mathrm{mg}$ versus $5 \mathrm{mg}$, the RR was 0.97 (95\% CI 0.46-2.02). The rate of major bleeding was $0.5 \%$ in the placebo group versus $0.2 \%$ in the $2.5 \mathrm{mg}$ apixaban group (RR 0.49 [95\% CI 0.09-2.64]), and $0.1 \%$ in the $5 \mathrm{mg}$ apixaban group (RR 0.25 [95\% CI 0.03-2.24]). The authors concluded that extended anticoagulation with apixaban at either treatment dose $(5 \mathrm{mg})$ or thromboprophylaxis dose $(2.5 \mathrm{mg})$ reduced the risk of recurrent VTE without increasing the rate of major bleeding. Table 2 summarizes the clinical trial data discussed earlier.

\section{Laboratory assays and monitoring}

Apixaban does not require dose adjustment or routine monitoring. However, the results of coagulation studies can provide relevance particularly in those patients experiencing major hemorrhage or requiring emergent surgery. In a single dose escalation study, peak aPTT, INR, and modified PT (higher sensitivity) increased by 1.2-, 1.6-, and 2.9-fold, respectively, from baseline following a $50 \mathrm{mg}$ dose. Although rapid and dose-related increases in these clotting assay parameters occurred, the magnitude of the increases following apixaban administration was considered minimal, thus the authors concluded that the INR and aPTT are not adequately sensitive for reliable evaluation of the pharmacodynamic effects of apixaban. ${ }^{26}$ Douxfils et al demonstrated a concentration-dependent prolongation of aPTT, PT, and dilute PT at increasing doses of apixaban, however also concluded none of these tests is sensitive enough to accurately estimate the pharmacodynamic effect of apixaban. The PTT-based lupus anticoagulant and dilute Russell's viper venom time were also found to be prolonged in a concentration-dependent manner. There was no effect on the ecarin clotting time, thrombin time, and reptilase time. Chromogenic protein $\mathrm{C}$ antigen or activity, free protein $\mathrm{S}$ antigen, and fibrinogen were also not influenced by apixaban. Depending upon the method utilized, the antithrombin assay may be affected by apixaban (FXa based assays should be avoided). It was also demonstrated that activated protein $\mathrm{C}$ resistance will be affected at higher concentrations of apixaban, and the intrinsic and extrinsic clotting factor assays were affected by the presence of apixaban. FXa chromogenic assays illustrated high sensitivity and a linear correlation depending upon the reagent and or the methodology utilized, thus serve as the assay of choice to measure for the presence of apixaban. ${ }^{27}$ Additional details regarding the effects of apixaban on coagulation assays are delineated in Table 3. 


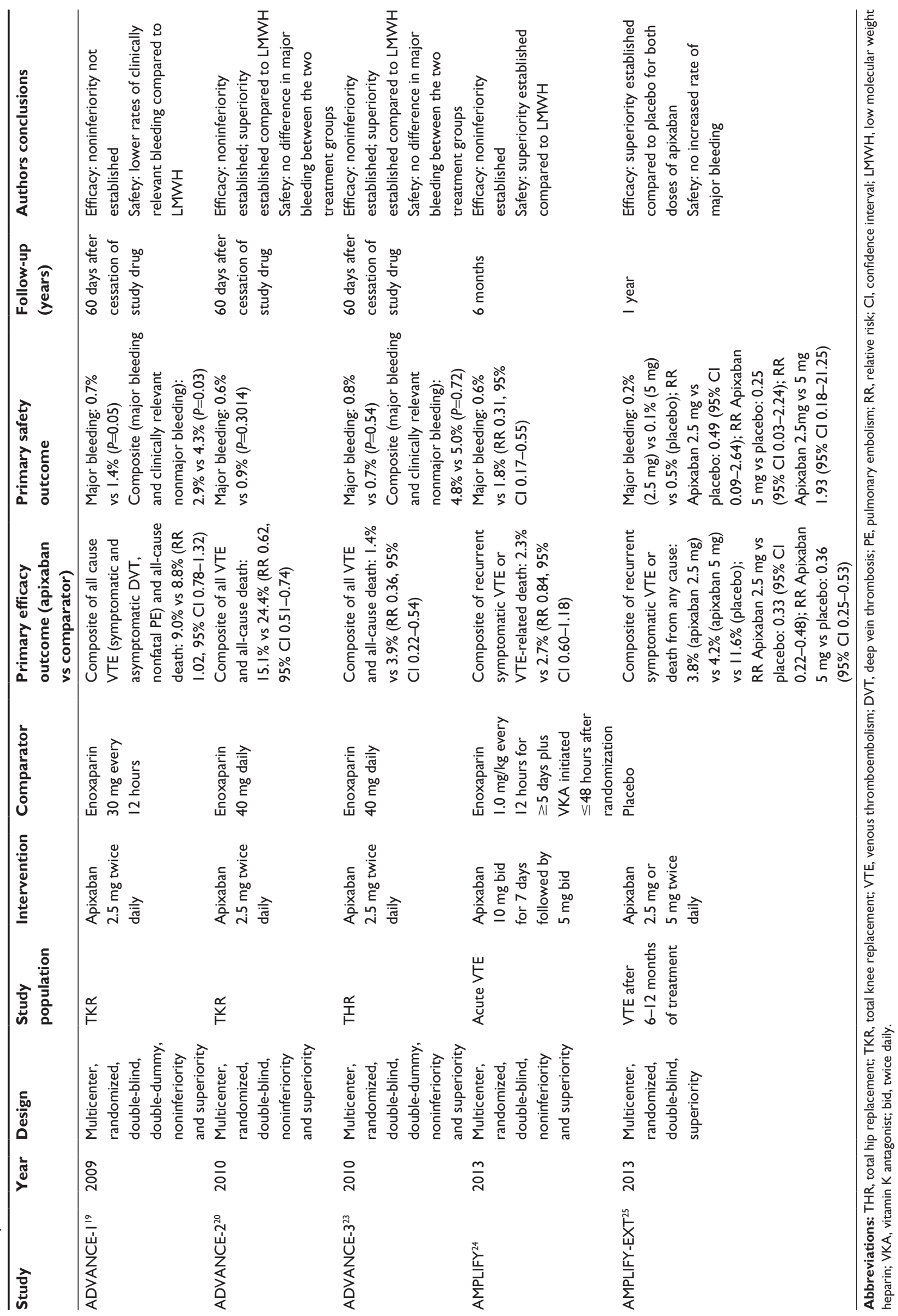


Table 3 Effect of apixaban on coagulation assays ${ }^{26,27}$

\begin{tabular}{ll}
\hline Measurement & Effect \\
\hline PT & Prolonged, dose-dependent \\
PTT & Prolonged, dose-dependent \\
INR & Increased, dose-dependent \\
PTT-based lupus anticoagulant & Prolonged, dose-dependent \\
dRVVT & Prolonged, dose-dependent \\
Thrombin time & No effect \\
Protein C activity & No effect \\
Free protein S antigen & No effect \\
Fibrinogen & No effect \\
Antithrombin & Potential effect depending upon \\
Factor Xa assay & specific assay \\
\hline
\end{tabular}

Abbreviations: PT, prothrombin time; PTT, partial thromboplastin time; INR, international normalized ratio; dRVVT, dilute Russell's viper venom time.

\section{Perioperative management}

Currently, no evidence-based guidelines exist for the management of apixaban in the perioperative setting. The package insert suggests apixaban should be discontinued at least 48 hours prior to elective surgery or invasive procedures with a moderate or high risk of bleeding, and 24 hours prior for procedures with a low risk of bleeding. ${ }^{13}$ The Working Group on Perioperative Haemostasis and the French Study Group on Thrombosis and Haemostasis suggest interruption of any of the TSOACs 24 hours prior to a procedure or surgery with a low risk of bleeding. If the procedure confers a moderate or high risk of bleeding, discontinuation of the TSOAC 5 days prior was recommended. ${ }^{28}$ Renal function may also be considered in the management of apixaban in the perioperative setting as further delineated in Table $4 .{ }^{29}$

The need for bridging anticoagulation may be determined based upon several risk factors. In patients with mechanical heart valves, $\mathrm{CHADS}_{2}$ (congestive heart failure, hypertension, age $>75$ years, diabetes mellitus, stroke history) score greater than $5,<6$ month history of stroke or transient ischemic attack, $<3$ month history of VTE, severe thrombophilia, deficiency of protein $\mathrm{C}$, protein $\mathrm{S}$, or antithrombin, or presence of antiphospholipidantibodies, the risk of recurrentVTE is $>10 \%$ per month and recurrent arterial thromboembolism (ATE) is $>10 \%$ annually. ${ }^{29,30}$ Thus, it is recommended that patients in this high risk category receive bridging anticoagulation. Patients with a bileaflet aortic valve with major risk factors for stroke, $\mathrm{CHADS}_{2}$ score of 3 or 4, or VTE within the past 3-12 months or active cancer are intermediate risk ( $4 \%-10 \%$ annual risk of ATE or $4 \%-10 \%$ per month risk of VTE). In the event that the periprocedural bleeding risk is low, bridging anticoagulation may be considered in these patients. Finally, in low-risk patients such as bileaflet aortic valve replacement (AVR) without major risk factors for stroke, $\mathrm{CHADS}_{2}$ score of 0-2 and no prior stroke or transient ischemic attack, or VTE $>12$ months prior, the risk of ATE is $<4 \%$ annually and VTE is $<2 \%$ per month, thus these patients do not require bridging anticoagulation. Table 5 addresses risk stratification and recommendations regarding perioperative bridging anticoagulation.

Apixaban may be resumed 24 hours postoperatively in patients who undergo a low bleeding risk surgery and 48-72 hours following surgery in those patients undergoing a high bleeding risk surgery, keeping in mind the quick onset of anticoagulant effect. ${ }^{31}$

\section{Special populations}

There is an absence of data regarding the use of apixaban in patients with chronic kidney disease, cancer, extreme body weight, pregnant women, and the elderly. Currently, in patients prescribed apixaban for reduction of the risk of stroke and systemic embolism in nonvalvular atrial fibrillation, the recommended dose is $5 \mathrm{mg}$ orally twice daily. ${ }^{13}$ However, in patients with at least two of the following, age $\geq 80$ years, body weight $\leq 60 \mathrm{~kg}$, or serum creatinine $\geq 1.5 \mathrm{mg} / \mathrm{dL}$, the recommended dose is $2.5 \mathrm{mg}$ orally twice daily. In the studies leading to the approval of apixaban, patients with end-stage renal disease with or without hemodialysis were not studied, specifically those patients with a $\mathrm{CrCl}$ less than $25 \mathrm{~mL} / \mathrm{min}$ were excluded in the atrial fibrillation and VTE trials. Thus, dosing recommendations for patients with nonvalvular atrial fibrillation are based on pharmacokinetic and pharmacodynamics

Table 4 Perioperative recommendations ${ }^{13,28-31}$

\begin{tabular}{llll}
\hline & Renal function & $\begin{array}{l}\text { Low bleeding risk } \\
\text { or minor surgery }\end{array}$ & $\begin{array}{l}\text { High bleeding risk } \\
\text { or major surgery }\end{array}$ \\
\hline $\begin{array}{l}\text { Preoperative } \\
\text { management }\end{array}$ & $\mathrm{CrCl}>50 \mathrm{~mL} / \mathrm{min}$ & $\begin{array}{l}\text { Hold 24 hours prior to surgery } \\
\text { (skip two doses) }\end{array}$ & $\begin{array}{l}\text { Hold 48 hours prior to surgery } \\
\text { (skip four doses) }\end{array}$ \\
& $\mathrm{CrCl} 30-50 \mathrm{~mL} / \mathrm{min}$ & $\begin{array}{l}\text { Hold 48 hours prior to surgery } \\
\text { (skip four doses) }\end{array}$ & $\begin{array}{l}\text { Hold } 72 \text { hours prior to surgery } \\
\text { (skip six doses) }\end{array}$ \\
$\begin{array}{l}\text { Postoperative } \\
\text { management }\end{array}$ & $\mathrm{CrCl}>50 \mathrm{~mL} / \mathrm{min}$ or $\mathrm{CrCl}$ & Resume 24 hours & Resume 48-72 hours \\
postoperative & postoperative
\end{tabular}

Abbreviation: $\mathrm{CrCl}$, creatinine clearance. 
Table 5 Risk stratification for perioperative arterial or venous thromboembolism ${ }^{29,30}$

\begin{tabular}{|c|c|c|c|}
\hline Risk stratification & High & Intermediate & Low \\
\hline & $\begin{array}{l}\text { - Any mechanical mitral valve } \\
\text { - Mitral/aortic caged ball or } \\
\text { tilting disc valve } \\
\text { - MHV with history of stroke } \\
\text { or TIA in previous } 6 \text { months } \\
\text { - CHADS }>5 \\
\text { - Atrial fibrillation with history of stroke } \\
\text { or TIA in previous } 3 \text { months } \\
\text { - Recent (within } 3 \text { months) VTE } \\
\text { - Deficiency of protein C, protein S, } \\
\text { or antithrombin } \\
\text { - Presence of antiphospholipid } \\
\text { antibodies }\end{array}$ & $\begin{array}{l}\text { - } \text { Bileaflet AVR plus major } \\
\text { risk factors for stroke } \\
\text { - } \text { CHADS }_{2} \text { score of } 3 \text { or } 4 \\
\text { - VTE within } 3-12 \text { months } \\
\text { - Heterozygous factor V Leiden, } \\
\text { prothrombin gene mutation } \\
\text { - Active cancer (treatment within } \\
6 \text { months or palliative) } \\
\text { - Recurrent VTE }\end{array}$ & $\begin{array}{l}\text { - Bileaflet AVR without major } \\
\text { risk factors for stroke } \\
\text { - } \text { CHADS }_{2} \text { score of } 0-2 \\
\text { - No prior stroke or TIA } \\
\text { - No VTE in previous } 12 \text { months }\end{array}$ \\
\hline $\begin{array}{l}\text { Anticoagulation } \\
\text { recommendations }\end{array}$ & Bridging anticoagulation recommended & $\begin{array}{l}\text { Bridging anticoagulation if low } \\
\text { bleeding risk }\end{array}$ & $\begin{array}{l}\text { Bridging anticoagulation not } \\
\text { required }\end{array}$ \\
\hline
\end{tabular}

data in end-stage renal disease patients on dialysis. The recommended dose for those patients on hemodialysis is $5 \mathrm{mg}$ orally twice daily. In a meta-analysis performed by Pathak et al bleeding risk with apixaban was noted to be lower when compared to conventional anticoagulants (enoxaparin and warfarin) and antithrombotics such as aspirin, in patients with mild renal insufficiency defined as $\mathrm{CrCl}$ 50-80 mL/min (RR 0.80 [95\% CI 0.66-0.96], $P=0.02$ ) and similar in patients with moderate to severe renal insufficiency defined as $\mathrm{CrCl}<50 \mathrm{~mL} / \mathrm{min}$ (RR 1.01 [95\% CI 0.49-2.10], $P=0.97){ }^{32}$

Apixaban is considered Pregnancy Category B and carries an increased risk of hemorrhage during pregnancy and delivery, thus its use is only recommended if the potential benefit outweighs the potential risk to the mother and fetus. Similarly, for nursing mothers it is unknown whether apixaban or its metabolites are excreted in human milk, thus discontinuation of apixaban is recommended in this population. ${ }^{13}$

Regarding the use of apixaban in the elderly, in the ARISTOTLE and AVERROES trials, which established the safety and efficacy of apixaban for the prevention of stroke or systemic embolism in patients with nonvalvular atrial fibrillation, $>69 \%$ of subjects were 65 and older, and $>31 \%$ were 75 and older. ${ }^{33,34}$ In the ADVANCE-1, ADVANCE-2, and ADVANCE-3 studies, $50 \%$ of subjects were 65 and older and $16 \%$ were 75 and older. ${ }^{19,20,23}$ In the AMPLIFY and AMPLIFY-EXT studies, $>32 \%$ of patients were 65 and older and $>13 \%$ were 75 and older. ${ }^{24,25}$ It is known that major and fatal bleeding is twice as high in patients 80 years of age and older on anticoagulation. ${ }^{35}$ At present there are no specific randomized controlled trials (RCTs) evaluating the use of TSOACs in the elderly compared to conventional anticoagulation. However, in a meta-analysis of ten RCTs including 25,031 patients 75 or older (three of which included apixaban), the risk of major or clinically relevant bleeding was not higher between apixaban and conventional therapy (5.1\% vs 7.3\%; OR 0.80 [95\% CI 0.43-1.51], $P=0.50) .{ }^{36}$

In patients with cancer, there is no published data regarding the efficacy and safety of the TSOACs in the management of acute VTE. In the AMPLIFY study, only $2.5 \%$ in the apixaban group and $2.8 \%$ in the conventional therapy group had active cancer. ${ }^{24}$ In the AMPLIFY-EXT study, only $1.1 \%-2.2 \%$ of patients had active cancer, and subgroup analysis was not performed. ${ }^{25}$ Moreover, the comparator group was placebo rather than continuation of at least prophylactic anticoagulation which most would advocate in patients with active cancer and a history of recent VTE. A Phase II pilot study evaluated the use of apixaban for primary VTE prophylaxis in patients with advanced malignancy receiving either first-line or second-line chemotherapy. Patients were randomized to 5,10 , or $20 \mathrm{mg}$ once daily of apixaban or placebo for 12 weeks within 4 weeks of the start of chemotherapy. Major bleeding occurred in 0,0 , and 2 of the patients receiving apixaban 5,10 , and $20 \mathrm{mg}$, respectively, and there were no fatal bleeds. Three placebo patients developed symptomatic VTE. Thus, apixaban may be safe and feasible for primary VTE prophylaxis in high-risk metastatic cancer patients receiving chemotherapy. ${ }^{37}$ Disadvantages to using apixaban in patients with cancer include alterations in GI absorption given vomiting and diarrhea secondary to chemotherapy as well as dependence on CYP3A4 metabolic pathways and potential drug-drug interactions. 


\section{Management of bleeding on apixaban}

One of the limitations to the use of the TSOACs is the lack of an antidote or reversal agent. However, when compared to aspirin, the risk for intracranial hemorrhage is similar with apixaban (RR 0.84 [95\% CI 0.38-1.87], $P=0.67$ ). ${ }^{38}$ Further, a recent meta-analysis showed that apixaban is associated with a lower risk of composite bleeding (including major or CRNM bleeding) and intracranial bleeding than VKAs. ${ }^{39}$ In the ARISTOTLE trial, there were fewer intracranial hemorrhages with apixaban compared to warfarin (hazard ratio 0.42 [95\% CI 0.30-0.58], $P<0.001$ ). ${ }^{40}$ Unlike VKAs such as warfarin, in which Vitamin $\mathrm{K}$ or fresh frozen plasma has been historically utilized, or UFH in which protamine is an effective antidote, no direct reversal agent exists for apixaban. ${ }^{13,41}$ Thus, bleeding complications pose a unique challenge. To date, no published RCTs have addressed the use of reversal agents for apixaban, and current evidence for TSOAC reversal is primarily extrapolated from in vitro experiments and animal models. Prothrombin complex concentrates (PCCs) are typically utilized in the event of life threatening hemorrhage, however recombinant activated factor VII is an acceptable alternative..$^{42}$ Perlstein et al studied the effects of four-factor PCCs on apixaban pharmacodynamics in 15 healthy subjects following the administration of apixaban $10 \mathrm{mg}$ orally twice daily. ${ }^{43}$ The four-factor PCC reversed the steady-state pharmacodynamic effects of apixaban in several coagulation assessments suggesting that four-factor PCCs may be useful in the management of bleeding in patients on apixaban.

A promising reversal agent for $\mathrm{FXa}$ inhibitors is andexanet alfa (r-Antidote, PRT064445), a recombinant FXa derivative that binds direct FXa inhibitors. In a dose-dependent fashion, it reversed the inhibition of FXa by direct FXa inhibitors and corrected the prolongation of ex vivo clotting times by such inhibitors. ${ }^{44}$ The use of andexanet alfa as a reversal agent is currently being studied in phase III clinical trials. ${ }^{45}$ Aripazine (PER977) is a small synthetic molecule that binds to TSOACs that is currently undergoing clinical development as a nonspecific TSOAC reversal agent. In thromboelastogram studies and rat-tail-transection bleeding assays, PER977 was shown to reverse anticoagulation with each of the new oral agents, including apixaban. ${ }^{46,47}$

\section{Conclusion}

Apixaban is currently FDA-approved to reduce the risk of stroke and systemic embolism in patients with nonvalvular atrial fibrillation, for the prophylaxis of DVT, which may lead to PE, in patients who have undergone TKR or THR, for the treatment of DVT and PE, and for the reduction in the risk of recurrent DVT and PE following initial therapy. The predictable pharmacokinetics, limited medication interactions, lack of required laboratory monitoring, and potentially improved cost-effectiveness ${ }^{48}$ render apixaban an attractive alternative to other anticoagulants such as warfarin. However, long-term safety data is not yet available, and RCT data is lacking in special populations. Moreover, a direct antidote is not yet FDA approved; however, several promising reversal agents are currently being studied.

\section{Disclosure}

The authors report no conflicts of interest in this work.

\section{References}

1. US Department of Health and Human Services. The Surgeon General's Call to Action to Prevent Deep Vein Thrombosis and Pulmonary Embolism. Washington, DC: US Department of Health and Human Services; 2008. Available from: http://www.surgeongeneral.gov/library/ calls/index.html. Accessed January 30, 2015.

2. Prandoni P, Kahn SR. Post-thrombotic syndrome: prevalence, prognostication and need for progress. Br J Haematol. 2009;145(3):286-295.

3. Kyrle PA, Rosendaal FR, Eichinger S. Risk assessment for recurrent venous thrombosis. Lancet. 2010;376:2032-2039.

4. Dobesh PP. Economic burden of venous thromboembolism in hospitalized patients. Pharmacotherapy. 2009;29(8):943-953.

5. Kahn S, Lim W, Dunn A, et al. Prevention of VTE in nonsurgical patients. Antithrombotic therapy and prevention of thrombosis, 9th ed: American College of Chest Physicians evidence-based clinical practice guidelines. Chest. 2012;141(2 Suppl):e195S-e226S.

6. Bristol-Myers Squibb Company. Coumadin (Warfarin Sodium) Tablets for Oral Use [prescribing information]. Princeton, NJ: Bristol-Myers Squibb Company; 2011. Available from: http://www.accessdata.fda. gov/drugsatfda_docs/label/2011/009218s1071bl.pdf. Accessed January 30, 2015.

7. O'Reilly R, Rytand D. "Resistance" to warfarin due to unrecognized vitamin K supplementation. N Engl J Med. 1980;303:160-161.

8. Suttie JW, Mummah-Schendel LL, Shah DV, Lyle BJ, Gregor JL. Vitamin $\mathrm{K}$ deficiency from dietary vitamin $\mathrm{K}$ restriction in humans. Am J Clin Nutr. 1988;47:475-480.

9. Booth SL, Charnley JM, Sadowski JA, et al. Dietary vitamin $\mathrm{K}_{1}$ and stability of oral anticoagulation: proposal of a diet with a constant vitamin $\mathrm{K}_{1}$ content. Thromb Haemost. 1997;77:504-509.

10. Wells PS, Holbrook AM, Crowther NR, Hirsh J. The interaction of warfarin with drugs and food: a critical review of the literature. Ann Intern Med. 1994;121:676-683.

11. Boehringer Ingelheim Pharmaceuticals, Inc. Pradaxa (Dabigatran Etexilate Mesylate) Capsules for Oral Use [prescribing information]. Ridgefield, CT: Boehringer Ingelheim Pharmaceuticals, Inc; 2015. Available from: http://www.accessdata.fda.gov/drugsatfda_docs/ label/2015/022512s024lbl.pdf. Accessed January 30, 2015.

12. Janssen Pharmaceuticals, Inc. Xarelto (Rivaroxaban) Tablets for Oral Use [prescribing information]. Titusville, NJ: Janssen Pharmaceuticals, Inc; 2015. Available from: http://www.accessdata.fda.gov/drugsatfda docs/label/2015/022406s012lbl.pdf. Accessed January 30, 2015.

13. Bristol-Myers Squibb Company. ELIQUIS (Apixaban) Tablets for Oral Use [prescribing information]. Princeton, NJ: Bristol-Myers Squibb Company; 2014. Available from: http://www.accessdata.fda. gov/drugsatfda_docs/label/2015/022512s024lbl.pdf. Accessed January 30, 2015. 
14. Daiichi Sankyo Co. Savaysa (Edoxaban) Tablets for Oral Use [prescribing information]. Tokyo, Japan: Daiichi Sankyo Co., LTD; 2015. Available from: http://www.accessdata.fda.gov/drugsatfda_docs/ label/2015/206316lbl.pdf. Accessed January 30, 2015.

15. Wong PC, Crain EJ, Xin B, et al. Apixaban, an oral, direct and highly selective factor Xa inhibitor: in vitro, antithrombotic and antihemostatic studies. J Thromb Haemost. 2008;6:820-829.

16. Eriksson BI, Quinlan DJ, Weitz JI. Comparative pharmacodynamics and pharmacokinetics of oral direct thrombin and factor Xa inhibitors in development. Clin Pharmacokinet. 2009;48:1-22.

17. Weitz J, Eikelboom J, Samama M. New antithrombotic drugs. Antithrombotic therapy and prevention of thrombosis, 9th ed: American College of Chest Physicians evidence-based clinical practice guidelines. Chest. 2012;141(2)(Suppl):e120S-e151S.

18. Falck-Ytter Y, Francis CW, Johanson NA, et al. Prevention of VTE in orthopedic surgery patients: antithrombotic therapy and prevention of thrombosis, 9th ed: American College of Chest Physicians evidence-based clinical practice guidelines. Chest. 2012;141 (2 suppl): e278S-e325S.

19. Lassen MR, Raskob GE, Gallus A, Pineo G, Chen D, Portman RJ. Apixaban or enoxaparin for thromboprophylaxis after knee replacement. N Engl J Med. 2009;361(6):594-604.

20. Lassen MR, Raskob GE, Gallus A, Pineo G, Chen D, Hornick P; ADVANCE-2 Investigators. Apixaban versus enoxaparin for thromboprophylaxis after knee replacement (ADVANCE-2); a randomized double-blind trial. Lancet. 2010;375(9717):807-815.

21. Schulman S, Kearon C; on behalf of the Scientific and Standardization Committee of the International Society on Thrombosis and Haemostasis Definition of major bleeding in clinical investigations of antihemostatic medicinal products in non-surgical patients. $J$ Thromb Haemos. 2005;3:692-694.

22. Huang J, Cao Y, Liao C, Wu L, Gao F. Apixaban versus enoxaparin in patients with total knee arthroplasty. A meta-analysis of randomized trials. Thromb Haemost. 2011;105(2):245-253.

23. Lassen MR, Gallus A, Raskob GE, Pineo G, Chen D, Ramirez LM;ADVANCE-3 Investigators. Apixaban versus enoxaparin for thromboprophylaxis after hip replacement. $N$ Engl J Med. 2010; 363(26):2487-2498.

24. Agnelli G, Buller HR, Cohen A, et al; AMPLIFY Investigators. Oral apixaban for the treatment of acute venous thromboembolism. $N$ Engl J Med. 2013;369(9):799-808.

25. Agnelli G, Buller HR, Cohen A, et al; AMPLIFY-EXT Investigators. Apixaban for extended treatment of venous thromboembolism. $N$ Engl J Med. 2013;368(8):699-708.

26. Frost C, Wang J, Nepal S, et al. Apixaban, an oral, direct factor Xa inhibitor: single dose safety, pharmacokinetics, pharmacodynamics and food effect in healthy subjects. Br J Clin Pharmacol. 2013;75(2): 476-487.

27. Douxfils J, Chatelain C, Chatelain B, Dogne JM, Mullier F. Impact of apixaban on routine and specific coagulation assays: a practical laboratory guide. Thromb Haemost. 2013;110(2):283-294.

28. Sié P, Samama C, Godier A, et al. Surgery and invasive procedures in patients on long-term treatment with direct oral anticoagulants: thrombin or factor-Xa inhibitors. Recommendations of the Working Group on perioperative haemostasis and the French Study Group on thrombosis and haemostasis. Arch Cardiovasc Dis. 2011;104(12):669-676.

29. Spyropoulos A, Douketis J. How I treat anticoagulated patients undergoing an elective procedure or surgery. Blood. 2012;120(15): 2954-2962.

30. Douketis J, Spyropoulos A, Spencer F, et al. Perioperative management of antithrombotic therapy. Antithrombotic therapy and prevention of thrombosis, 9th ed: American College of Chest Physicians evidence-based clinical practice guidelines. Chest. 2012;141(2 Suppl): e326S-e3350S.
31. Nutescu EA. Oral anticoagulant therapies: balancing the risks. Am J Health Syst Pharm. 2013;70(10 Suppl):S3-S11.

32. Pathak R, Pandit A, Karmacharya P, et al. Meta-analysis on risk of bleeding with apixaban in patients with renal impairment. Am J Cardiol. 2015;115:323-327.

33. Granger C, Alexander J, McMurray J, et al. Apixaban versus warfarin in patients with atrial fibrillation. $N$ Engl J Med. 2011;365(11): 981-992.

34. Connolly S, Eikelboom J, Joyner C, et al. Apixaban in patients with atrial fibrillation. $N$ Engl J Med. 2011;354(9):806-817.

35. Lopez-Jimenez L, Montero M, Gonzalez-Fajardo JA, et al. Venous thromboembolism in very elderly patients: findings from a prospective registry (RIETE). Haematologica. 2006;91:1046-1051.

36. Sardar P, Chatterjee S, Chaudhari S, Lip G. New oral anticoagulants in elderly adults: evidence from a meta-analysis of randomized trials. J Am Geriatr Soc. 2014;62:857-864.

37. Levine $\mathrm{MN}, \mathrm{Gu} \mathrm{C}$, Liebman $\mathrm{HA}$, et al. A randomized phase II trial of apixaban for the prevention of thromboembolism in patients with metastatic cancer. J Thromb Haemost. 2012;10(5):807-814.

38. Hankey GJ. Intracranial hemorrhage and novel anticoagulants for atrial fibrillation: what have we learned? Curr Cardiol Rep. 2014; 16(5):480

39. Touma L, Fillon K, Atallah R, et al. A meta-analysis of randomized controlled trials of the risk of bleeding with apixaban versus vitamin $\mathrm{K}$ antagonists. Am J Cardiology. 2015;115:533-541.

40. Hylek E, Held C, Alexander J, et al. Major bleeding in patients with atrial fibrillation receiving apixaban or warfarin. J Am Coll Cardiol. 2014;63(20):2141-2147.

41. Pfizer Labs. Heparin Sodium Injection for Intravenous or Subcutaneous Use [prescribing information]. New York, NJ: Pfizer Labs; 2011. Available from http://www.accessdata.fda.gov/drugsatfda_docs/ label/2011/201370s0001bl.pdf. Accessed January 30, 2015.

42. Siegal DM. Managing target-specific oral anticoagulant associated bleeding including an update on pharmacological reversal agents. J Thromb Thrombolysis. Epub 2015 Jan 14

43. Perlstein I, Wang Z, Song Y, et al. Reversal of apixaban anticoagulation by 4 -factor prothrombin complex concentrates in healthy subjects [abstract]. Blood. 2014;124(21):345.

44. Lu G, DeGuzman FR, Hollenbach SJ, et al. A specific antidote for reversal of anticoagulation by direct and indirect inhibitors of coagulation factor Xa. Nat Med. 2013;19(4):446-451.

45. Crowther M, Gold A, Lu G et al. ANNEXA-A PART 2: A phase 3 randomized, double-blind, placebo-controlled trial demonstrating sustained reversal of apixaban-induced anticoagulation in older subjects by andexanet Alfa (PRT064445), a universal antidote for factor Xa (FXA) inhibitors. J Thromb Haemost. 2015;13 (Suppl. 2). Abstract LB004.

46. Laulicht B, Bakhru S, Lee C, et al. Small molecule antidote for anticoagulants [abstract]. Circulation. 2012;126:A11395.

47. Ansell JE, Bakhru SH, Laulicht BE, et al. Use of PER977 to reverse the anticoagulant effect of edoxaban. $N$ Engl J Med. 2014;371(22): 2141-2142.

48. Revankar N, Patterson J, Kadambi A, et al. A Canadian study of the costeffectiveness of apixaban compared with enoxaparin for post-surgical venous thromboembolism prevention. Postgrad Med. 2013;125(4): $141-153$. 


\section{Publish your work in this journal}

Therapeutics and Clinical Risk Management is an international, peerreviewed journal of clinical therapeutics and risk management, focusing on concise rapid reporting of clinical studies in all therapeutic areas, outcomes, safety, and programs for the effective, safe, and sustained use of medicines. This journal is indexed on PubMed Central, CAS,

EMBase, Scopus and the Elsevier Bibliographic databases. The manuscript management system is completely online and includes a very quick and fair peer-review system, which is all easy to use. Visit http://www.dovepress.com/testimonials.php to read real quotes from published authors.

Submit your manuscript here: http://www.dovepress.com/therapeutics-and-clinical-risk-management-journal 